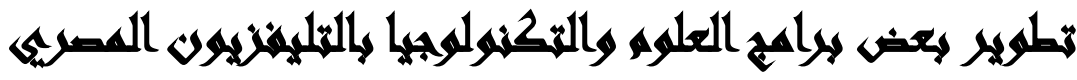

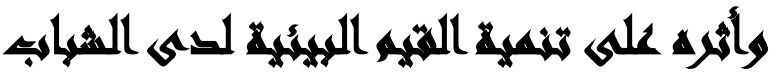

\section{[19]}

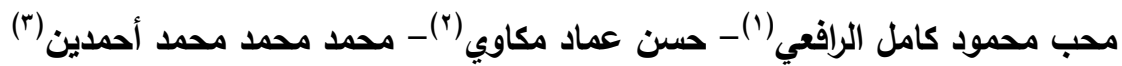

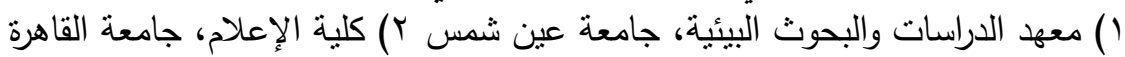

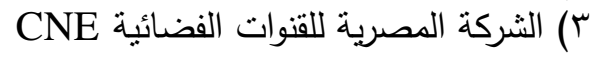

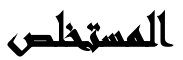

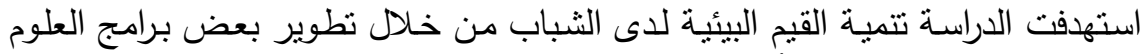

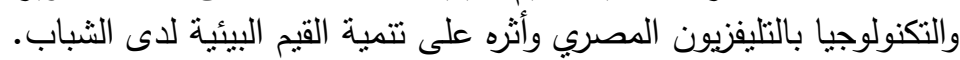

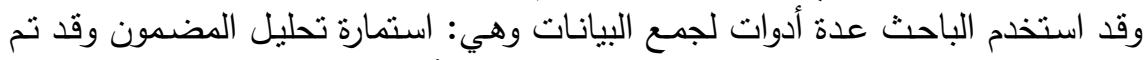

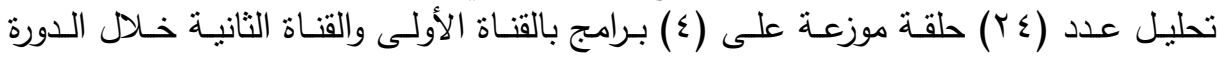

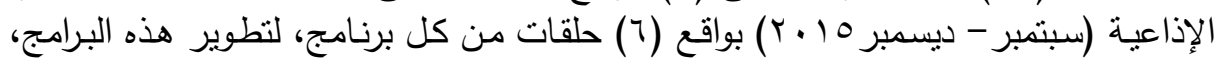

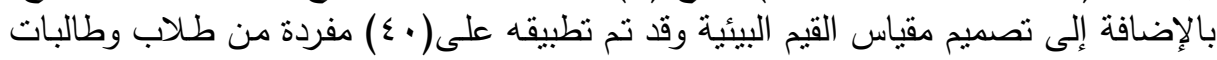

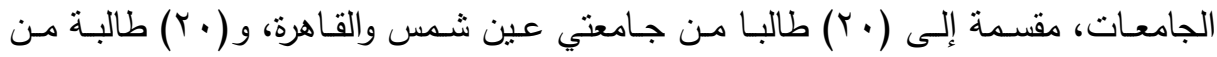

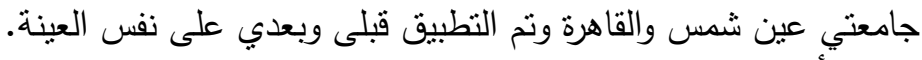
وكانت أهم نتائج الدراسة ما يلئي

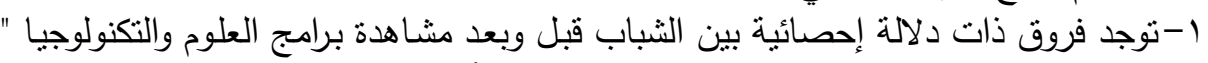

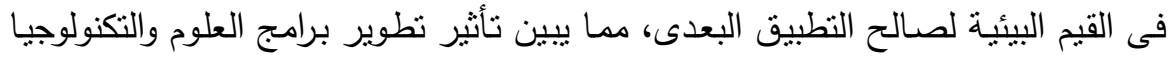

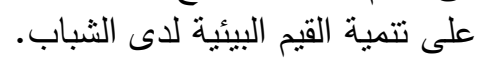

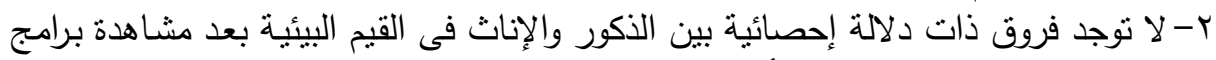

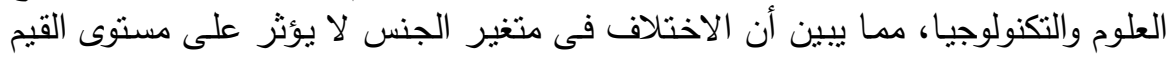

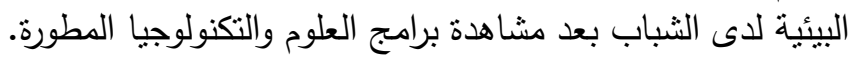

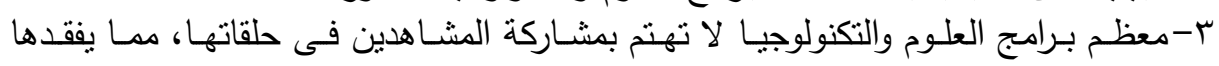

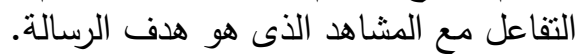

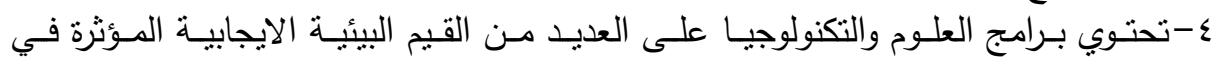
المشاهدين، ولكنها تفقتد التقديم في شكل جذاب. 


\section{المهامبها}

نحن نعيش بدايات القرن الحادي والعشرين وفى عصر وصف بأنه عصر العلم

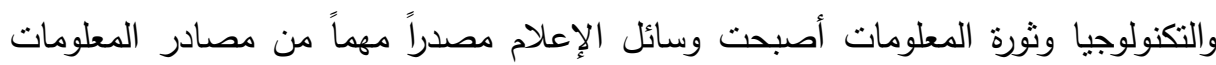

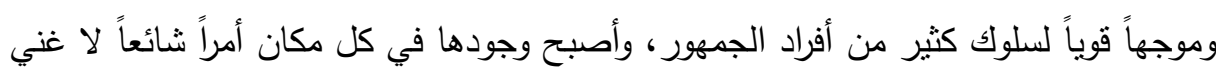

وخلال السنوات الماضية أثتتت العديد من الدراسات ازدياد عدد الساعات التي يقضيها الجمهور مع وسائل الإعلام الجماهيري، وهذا مؤشر قوي ومهم على زيادة تعرض الجمهور

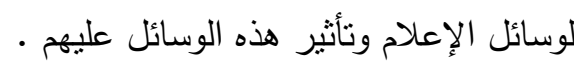

وفى عالم اليوم نتزايد احتياجات المجتمعات إلى المعلومات المات والأخبار، ويزداد استهلاك

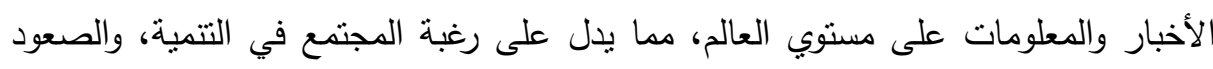
إلى ركب الحضارة، حيث إن المشاركة العالمية والتفاعل يعين المجتمع على نطوير نفسه.

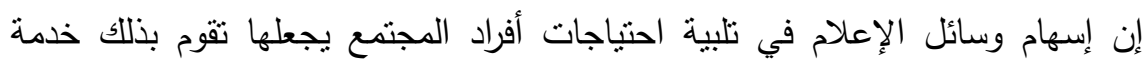
عامة للمجتمع.. هذا إذا قامت وسائل الإعلام بالوظائف الاجتماعية المناطة على الته الوجاته

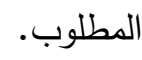

وتبرز أهمية التليفزيون - بوجه خاص - في المجالات ذات الصلة بالجوانب التعليمية والتربوية، ويأتي في مقدمة الوسائل التعليمية والتنربية - غير النظامية - من حيث الأهمية

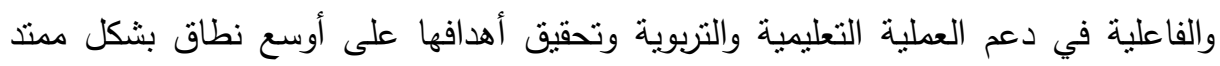
وشامل لمختلف نوعيات وشرائح الجمهور، إلى جانب دوره الخاص المدعم والمكمل للعملية التعليمية والتربوية في مؤسسات التعليم النظامي. ويندرج الإعلام البيئي في إطار نوعيات الإعلام المتخصص ذائسيات ذات الصلة المباشرة بالجوانب التعليمية والتربوية، والتي بدأتت تحظى باهتمام كبير مع تصاعد الإتهات الإعمام بقضايا البيئة، وتعقد المشكلات البيئية الأمر الذي يعكس أهمية دور التليفزيون في هذا المجال. 


\section{منوحلم التراسلة}

تركز الخطط الإعلامية السنوية لإتحاد الاذاعة والتلفزيون علي ضرورة مراعاة البعد

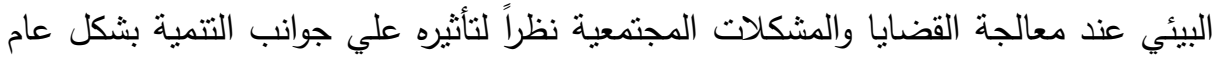
والتتمية المستدامة بشكل خاص. وقد تبين للباحثين من خلال الثقارير الأحصائية (اتحاد الإذاعة والتليفزيون، للعام

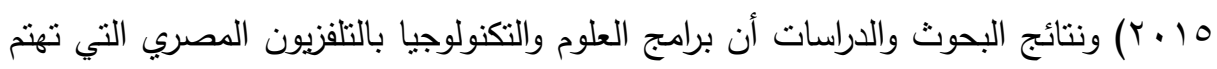

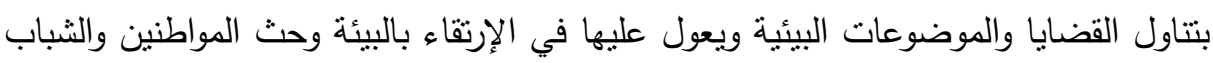
منهم علي وجه الخصوص علي تبنى توجهات وقيم إيجابية تجاه البيئة، هذه البرامج قلبلة جداً وتقدم في أوقات غير مناسبة للغالبية العظمي من المشاهدين، وتقدم في قوالب وأنثكال تقليدية ومن هنا مشكله الدراسة تتحدد: "بقصور برامج العلوم والتكنولوجيا في التلفزيون عن تتمية المهارات والقيم البيئية لدي الثباب" وعلي ذللك يتحدد موضوع الدراسة في " تطوير بعض بله برامج العلوم والتكنولوجيا في التليفزيون من اجل استخدامها الاستخدام الأمثل في تتمية المهارات والقيم البيئية لدي جماهير المشاهدين وخاصة الثباب منهم

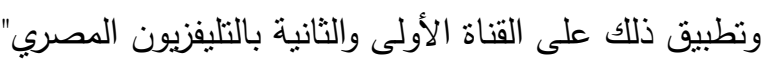

ويالتالي فإن مجال الدراسة يتحدد في محورين أو بعدين أساسين هما: 1- أهمية التليفزيون في نشر الثقافة البيئية والمساهمة في تتمية القيم البيئية ويتمنل فيما يمكن أن يقدمه التليفزيون من إسهامات في نشر الوعي البيئي وتطويره وتوسيع قاعدة الثقافة البيئية في ضوء نظرية الغرس الثقافي حيث تذهب هذه النظرية إلى القول بأن مداومة التعرض للتليفزيون -ـلفترات طويلة - تتمي Cultivate لاي المشاهد اعتقاداً بأن العالم الذي يراه على شاشة التليفزيون، إن هو إلا صورة مطابقة للعالم الواقعي الذي يحياه

$$
\text { .(p.402 ، Becker) }
$$

وتفترض نظرية الغرس الثقافي أن الأشخاص الذين يتعرضون لكميات ضخمة من

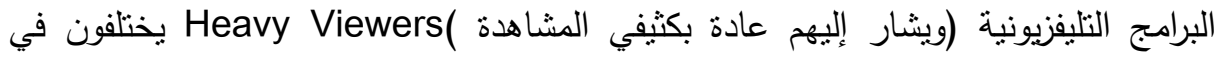
إدراكهم للواقع الاجتماعي عن( أولئك الذين يشاهدون أقل، ذلك أن كثيفي المشاهدة سيكون

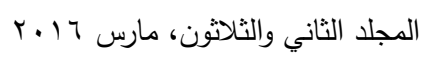


لديهم مقدرة أكبر على إدراك الواقع المعيثي بطريقة متسقة مع الصور الذهنية التي يعكسها التليفزيون.

(Singnorielli,N.,\&Morgan, , p.9.) r- ارتباط المضمون العلمي والثقافة البيئية في التليفزيون بسياسة الدولة وخطط اتحاد الإذاعة والتليفزيون من ناحية ومن ناحية أخرى ارتباط هذا المضمون بحاجات الجماهير ورغباتها في شتى نواحي العلم والمعرفة في مجال البيئة . وذللك عن طريق قياس مدى التزام مواد وبرامج العلوم والتكنولوجيا بالسياسات والخطط والأهداف الخاصة بالتتمية القومية الثاملة. طبقا لما ورد في الخطة الخمية للاولة والخطط الاعلامية الخاصة باتحاد الاذاعة والتليفزيون الثانوية.

\section{ranly}

ويمكن بلورة هذه المشكلة في التساؤل الرئيسي التالي: ما فاعلية تطوير بعض برامج العلوم

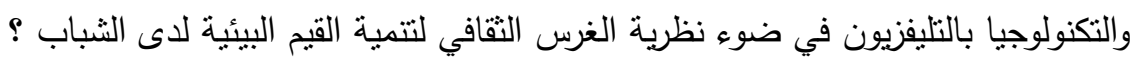

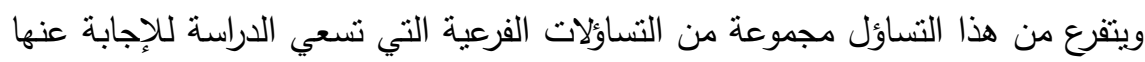
ووضع حلول علمية وعملية لها:

1-ما القيم البيئية التي يجب أن تتناولها برامج العلوم والتكنولوجيا بالتليفزيون المصري؟

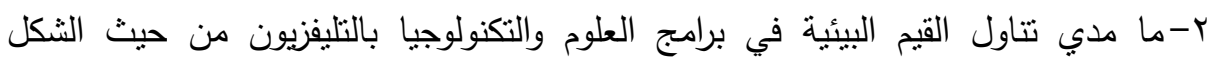

والمضمون ؟

r-ما التطوير المقترح لبعض برامج العلوم والتكنولوجيا ؟ ؟ بمان

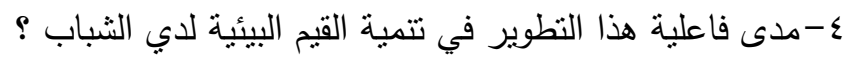




\section{أهمية الصوراسة}

أولاً: الأهمية النظرية للاراسة:

• إبراز أهمية برامج العلوم والتكنولوجيا وتخصيص مساحة ملائمة لها على الخريطة

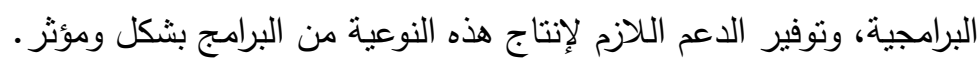

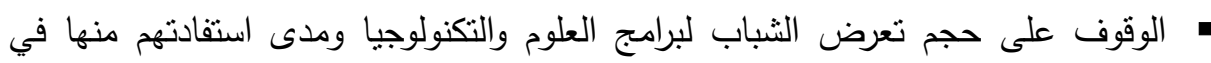

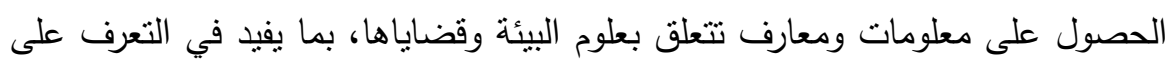
مدى فاعلية وتأثير البرامج على الثباب في تكوين قيمهم تجاه البيئة. ثانياً: الأهمية التطبيقية للاعراسة:

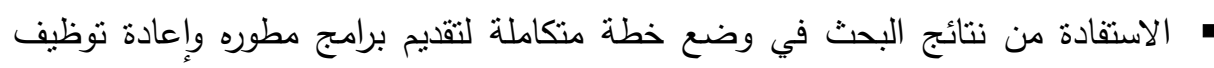
برامج العلوم والتكنولوجيا في خدمة نشر الثقافة والتربية البيئية باستخدام المداخل والإستمالات المستندة على نظريات الإعلام الحديثة.

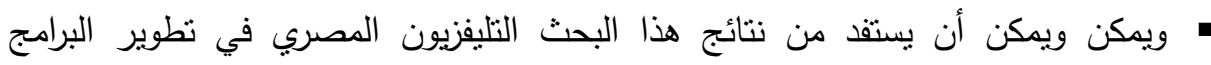

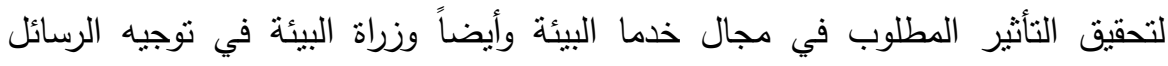
والحملات الاعلامية الؤثرة وكنلك الثباب الذين هم الهدف والمحرك الأكثر الأكثر

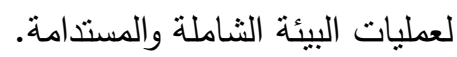

\section{أهساهيت الصراسمة}

يستهدف البحث تنمية المهارات والقيم البيئية لاى الثباب من خلال: ا. نطوير أساليب المعالجة البرامجية التليفزيونية لقضايا البيئة باستخدام الدداخل العلية لئلية

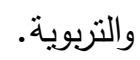
r. تكثيف الاهتمام ببرامج العلوم والتكنولوجيا وتطويرها لتنمية القيم ، ولجمهور الثباب بوجه خاص. (- ماص. r. الإسهام في وضع أسس جديدة للتطوير البرامجى لتنمية القيم البيئية لاى الثباب.

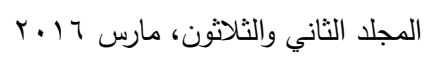




\section{مهذاهبه التراسمة}

ا-مفهوم الإعلام البيئي: "كل نشاط إنساني يؤثر في البيئة من خلال وسائل الإعلام المختلفة لكي يُوَّعي الجمهور ويمده بكافة المعلومات والحقائق والآراء عن القضايا البيئية

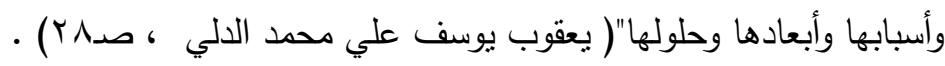
التعريف الإجرائي: هو الإعلام الذى يتخصص فى عرض وتتاول وشرح القضايا والموضوعات المتعلقة بالبيئة، ويعمل على توضيح المفاهيم البيئية، من خلال إحاطة الثباب المنلقي والمستهدف بكافة الحقائق، والمعلومات الموضوعية.. ويعمل على عرضعلى عرضع وتحليل وايجاد الحلول للمشكلات البيئية بواسطة الخبراء والمتخصيين ومتابعة التتفيذ مع المسئولين.. بما يسهم في جذب انتباه الثباب واقتاعهم بترشيد السلوكيات البيئية، والمشاركة الفعالة فى ومئه

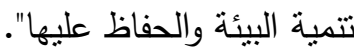
ا ـ برامج العلوم والتكنولوجيا: برامج العلوم والتكنولوجيا (بالتليفزيون) هي البرامج التي تؤدي وظائف الإعلام العلمي المتمثلة في نقل المعلومات أو المعرفة العلمية إلى الجماهير العريضة عن طريق العمل الاتصالي Act of Communication عبر التليفزيون كوسيلة

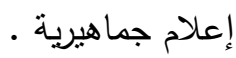

وتعني برامج العلوم والتكنولوجيا بتقديم مجموع المعارف الإنسانية والخبرات في فروع

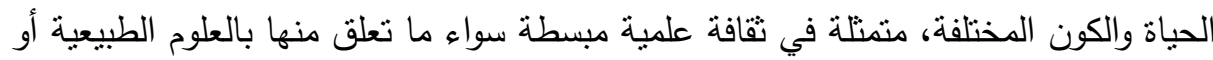
الإنسانية ، وتهنم بالتعريف بتطبيقات العلوم الحديثة والتكنولوجيا في مختلف مجالات الحياة، وتعد النافذة التي بطل منها المشاهدون على التطور والتقدم العلمي والتكنولوجي في العالم .

$$
\text { (سوزان القليني ، صلاح مدكور ، صد الفه (1). }
$$

التعريف الإجرائي: هي البرامج التى تهتم بتقديم مجموع المعارف الإنسانية والخبرات في فروع الحياة والكون المختلفة ، منمثلة في ثقافة علمية مبسطة سواء ما تعلق منها بالعلوم الطبيعية

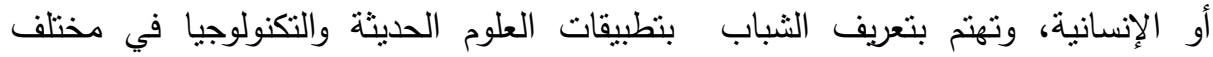
مجالات الحياة، وتحثهم على اكتساب وتبني مهارات وقيم للتعامل مع البيئة وحل مشكلاتها. 
ץ - مفهوم القيم البيئية: هي محصله مجموعة من الاتجاهات البيئية التي تصبح في إطار نسقى معين، يكتسبها الفرد خلال تفاعله الاجتماعي مع الآخرين وتعمل كموجهات

لسلوكه وتحدد استيعابه إزاء البيئة التي يعيش فيها (عماد الدين الوسيمي : 990 ) التعريف الإجرائي: "هي مجموعه من المعتقدات أو القواعد أو الاحكام التى تتبثق من جماعه لهاءئه ويكتسبها الثباب من خلال تفاعلهم مع المجتمع والبيئة التى يعيشون فيها.. تؤثر في تكوين شخصيته، وتتأثر بالبيئة الثقافية والاجتماعية وأسلوب تتاولها للقضايا والموضوعات المتعلقة بالبيئة.. تستخدم في تقويم الممارسات الإنسانية.. وهى المعايير التى توجه سلوك الثنباب

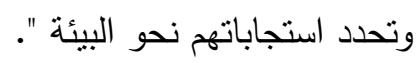

\section{الاطار النظريه للتصراسة}

تمنل المنطلق النظري لهذه الدراسة في نظرية واحدة هي:

- نظرية الغرس الثقافي: وتعد نظرية الغرس من بين النظريات التى تدرس التأثير طويل

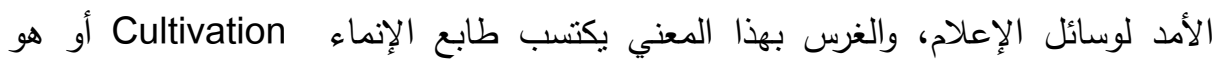

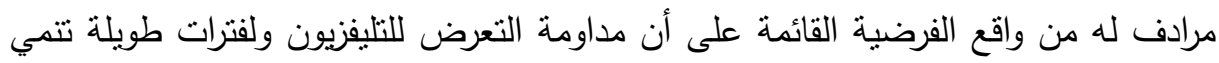

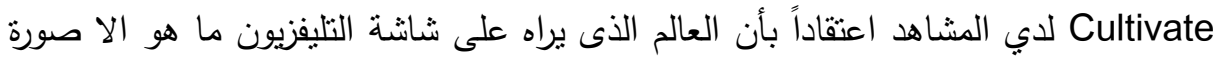

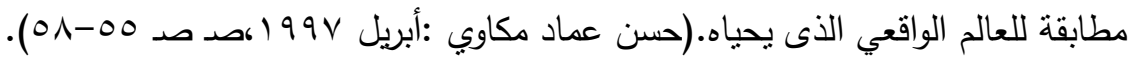
ای ان نظرية الغرس الثقافي تفترض ان المشاهدة الكثيفة للتليفزيون تؤدي الى ادراك

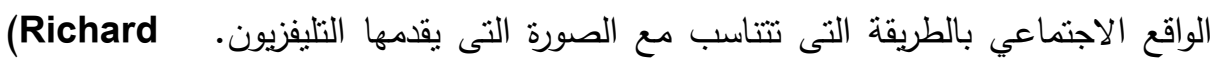
campbell \& (etal) 2003) P524) ويعد جورج جيرنر هو مؤسس نظرية الغرس التقافي ، عندما بدا جيرنر دراسته الخاصة

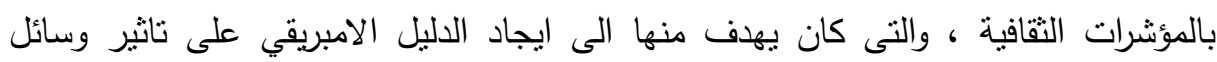

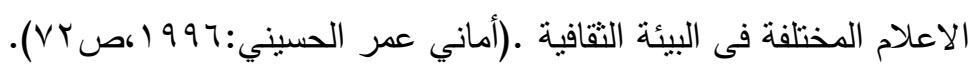
وتقوم نظرية الغرس على الفرض الرئيسي الذي يشير إلى أن الأفراد الذين يتعرضون

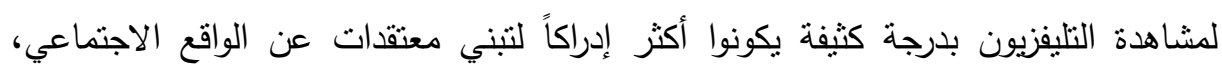

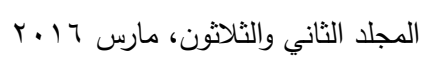


بحيث يتطابق الواقع مع الصور الذهنية والنماذج والأفكار التي يقدما التليفزيون. وتقوم نظرية الغرس على مجموعة من الفروض الفرعية هي :

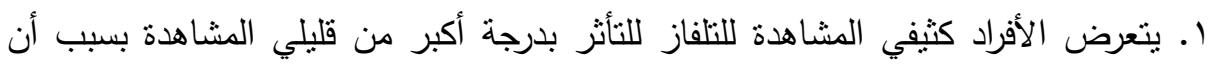
قليلي الششاهدة يتعرضون على مصادر منتوعة مثل التليفزيون ومصادر شخصية أخرى. r. يختلف التلفاز عن غيره من وسائل الاتصال الأخرى، وأن الغرس الذي يحدثه هو نتيجة التعرض والاستخدام غير الانتقائي من قبل الجمهور . بان.

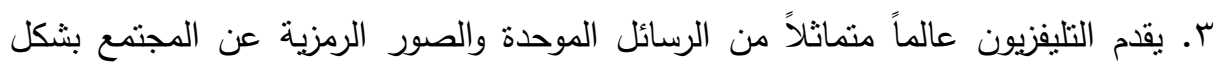
موحد أو منتشابه عن الواقع الحقيقي. ع. يزيد حدوث الغرس عند اعتقاد المشاهدين بأن الدراما واقعية وتنعى لتقديم حقائق بدلاً من الن الخيال و النماذج المفسرة لعملية الغرس علب علعرس

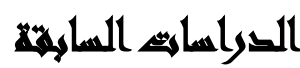

\section{(1)دراسة "تهلة مظفر، . . . . "عن برامج التوعية البيئية فى التليفزيون المصرى والسورى.}

استهدفت الدراسة التعرف على حجم اهتمام التليفزيون المصرى والسورى بنشر الوعى والثقافة البيئية والكثف عن وجود أو عدم وجود خطة إعلامية إستراتيجية لإعداد البرامج

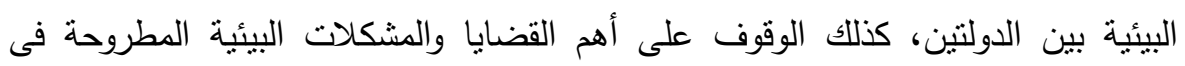
برامج التوعية البيئية. وقد استخدمت الباحثة أسلوب تحليل محتوى البرامج البيئية فى التليفزيون المصرى

$$
\text { والسورى وأهم نتائج الدراسة: }
$$

- أن البرامج البيئية فى التليفزيون المصرى تخصصت باتئية بالقضايا البيئية فى حين أن برامج

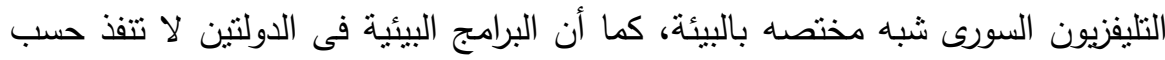
الخطط السنوية الإعلامية. 
- تسعى البرامج البيئية فى الدولتين إلى النجاح فى اقناع المواطنين بتغيير أفكارهم

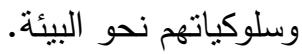

- ل لا يزال تتفيذ البرامج البيئية داخل الأستوديو أى مازالت أسيرة النمط التقليدى للبرامج.

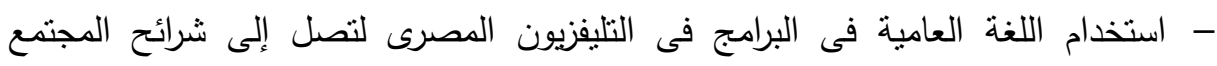
الواسعة، أما التليفزيون السورى والتمسك باللغة الفصحى مع ميل عام إلى التبسيط.

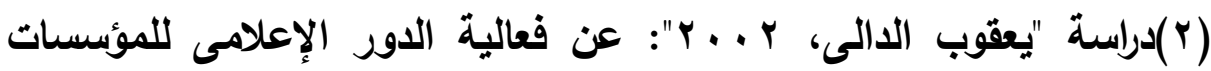
البيئية فى تنمية الوعى البيئى لاى الثباب. استهدفت الدراسة الوقوف على مدى تأثير المطبوعات والبرامج البيئية التى تصدرها

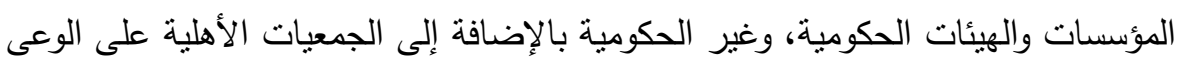
البيئى لدى الثباب.وقد استخدم الباحث تحليل مضمون بعض البرامج والنشرات والكتيات

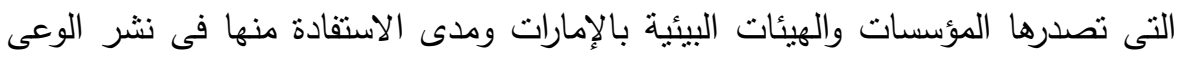
البيئى، كما يتضمن هذا البحث التعرف على دور العاملين والقائمين بالاتصال بأقسام التوعية والإعلام البيئى بالمؤسسات والهيئات البيئية بالإمارات لتوعية الجماهير لمعرفة لئية وعيهم بالمشكلات والقضايا البيئية فى مجال الوعى البيئى والمحافظة على الموارد الطبيعية.وقد تم اختبار عينة البحث بطريقة عشوائية طبقية قوامها ( . . r) مفردة تم تقسيمها إلى مجموعنين الأولى تجريبية والثانية ضابطة.

وقد تمثلت أهم نتائج الاراسة: - لم تركز المطبوعات على قضية بعينها ولكن تتوعت القضايا والمشكلات. - تدنى مسنوى الوعى البيئى لدى الثباب قبل تطبيق البرنامج.

- ضعف التعاون بين المؤسسات البيئية بالدولة مع وسائل الإعلام تجاه نشر الوعى لنعى البيئى.

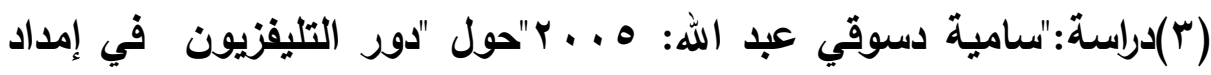
المرأة المصرية بالمعلومات البيئية" دراسة في إطار نظرية فجوة المعرفة. - ـ وتهدف الدراسة إلى التعرف على دور التليفزيون في إمداد المرأة في المناطق ذات المستوي الاجنماعي والاقتصادي المرتفع والمنخفض بالمعلومات المتعلقة بالفضاء والمشكلات

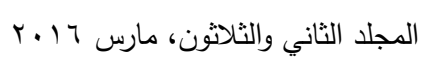


البيئية ودراسة المتغيرات التى تقوم على اكتثافها لهذه المعلومات ومستوي الاهتمام

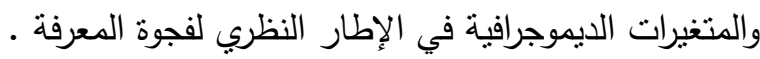
- وخلصت إلى أن القالب الدرامي هو أفضل الأشكال لدي السيدات يليها الرسائل النوعية

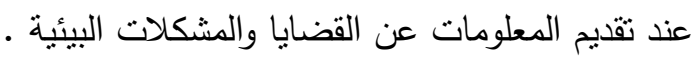

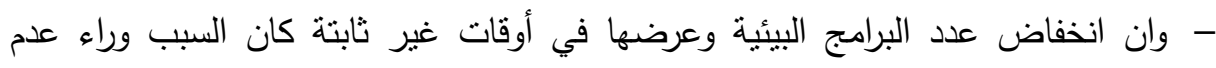

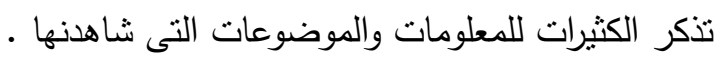

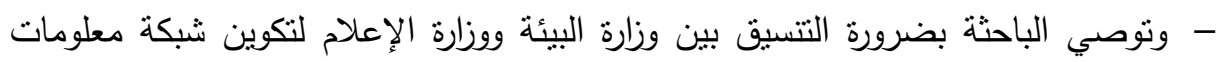
لتوفير البيانات والمعلومات الحديثة للإعلاميين.

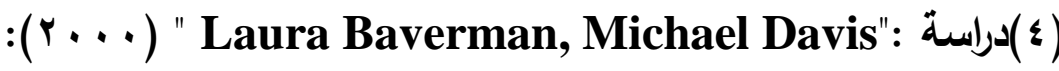
فقد استهدفت تقييم اتجاهات وقيم طلبة جامعة ميامي، ومواقفهم نحو البيئة الطبيعية، والتعرف على العلاقة بين القيم البيئية التي يحملونها ومستوى تقديرهم لبيئة أماكن إقامتهم خارج

- وجود فروق ذات دلالة إحصائية بين اتجاهات الطلبة الذين يقطنون المناطق الحضرية وأقرانهم في المناطق الريفية،حيث تبين أن اتجاهات طلبة الأرياف نحو البيئة، ومستوى درى دابه الوعي بحمايتها من الأخطار أكثر ايجابية من الطلبة في المناطق الحضرية.

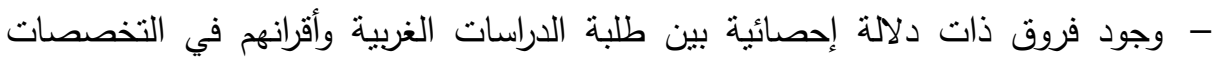
الأخرى، حيث أوضحت النتائج ايجابية اتجاهاتهم البيئية، ونضج وعيه دانهم البيئي.

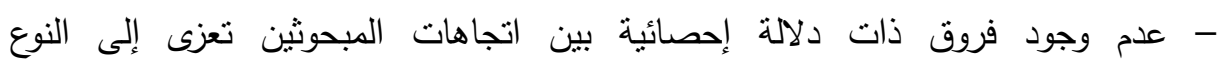

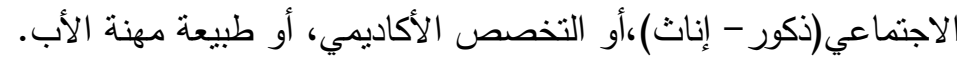

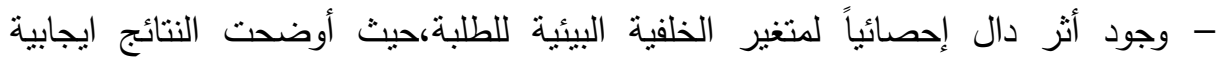
اتجاهاتهم البيئية. 
(•)دراسة: "'"(2003)"Emily E. McMillan) فقد هدفت إلى التعرف على مدى تأثثر دراسة المواد والمقررات البيئية في قيم طلبة جامعة Dalhousie وأخلاقهم البيئية .

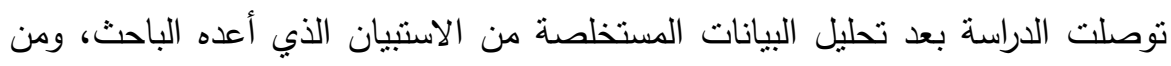

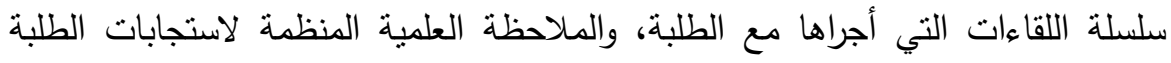

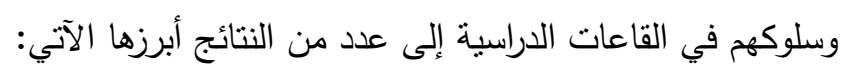

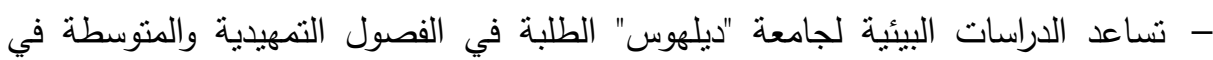

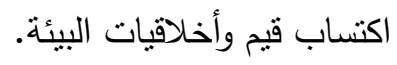

- تركزت استجابات الطلبة خلال المقابلة الأولى في الفصل الأول، على مثاكل تلوث الهواء

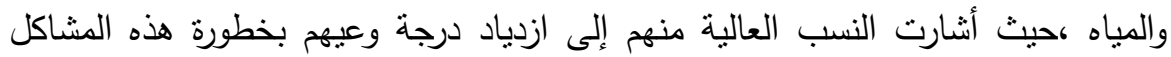

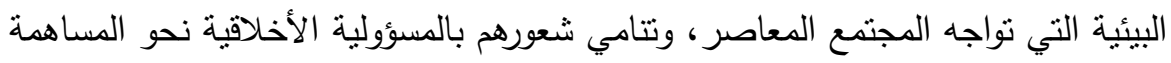
في التقليل منها.

- وتركزت استجابات المبحوثين لدى مقابلتهم اللمرة الثانية في الفصل الثاني على استنزاف الموارد البيئية ودرجة خطورتها، كما انسعت دائرة الاهتمام بالمشاكل البيئية ذات الصلة الصاتل

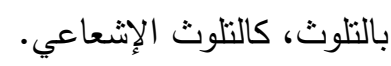
- روئية المبحوثين من الطلبة نحو كوكب الأرض وتركيزهم على قضاياها البيئية مقارنة

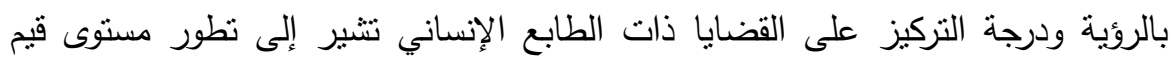
الاهتمام بالمشكلات التي تواجه بيئة الأرض لديهم.

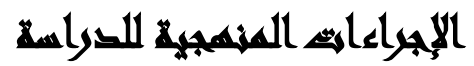

• نوع الدراسة والمنهج والأدوات المستخدمة: تنتمي هذه الدراسة إلى الدراسات الوصفية

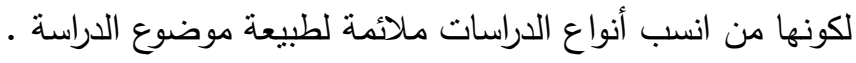

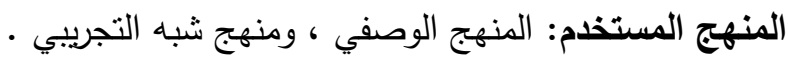




\section{الأدوات التي استخدمها الباحث هي :}

1- تم تصميم إستمارة تحليل المضمون لتحليل برامج القتاة الأولى: " سواعد مصريه -

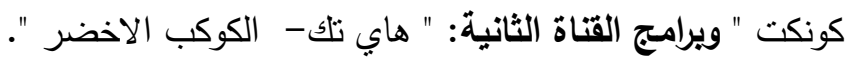
وشملت فئات التحليل : أ- فئات الشكل: ( البيانات الأساسية للبرامج - نوقيت الاذاعة - دورية إذاعة البرنامج - مدة

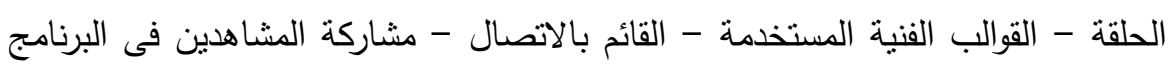
- مواقع التصوير )

ب- فئات المضمون: (المواد الفيلمية والمؤثرات المرئية - مداخل الاقناع المستخدمة الاستمالات العاطفية - الاستمالات المنطقية - القبم البيئية التى تتاولتها برامج العلوم والتكنولوجيا ).

وتم اجراء اختبارات الصدق بعرض استمارات التحليل على مجموعة من المحكمين واجراء بعض التعديلات في ضوء الملاحظات التي أوصى بها المحكمن. وكذلك اختبار

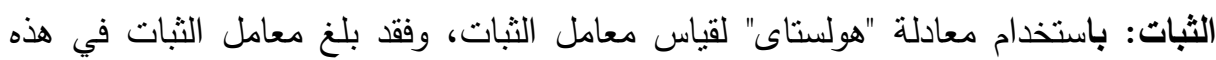
الدراسة نسبة 0 , 19 \% ؛ وهي قيمة مرتفعة تدل على صلاحية المقياس إلى حد كبير .

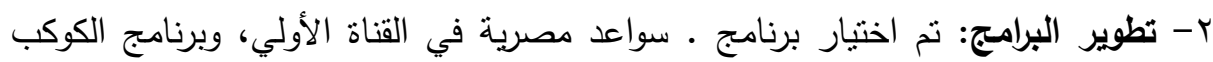

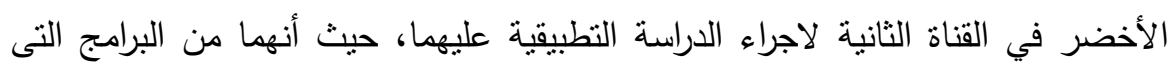

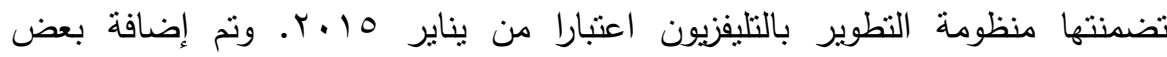

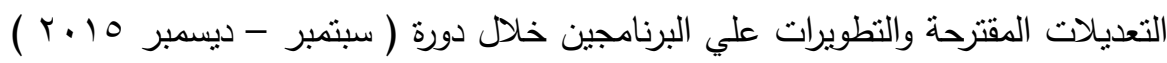

$$
\text { كان أهمها - من حيث الثكل: }
$$
- تغيير نتر البرنامج: ليصبح بشكل جذاب ومنضمناً بعض اللقطات والجرافيك الذي يوحي

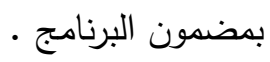
- تطوير الفواصل: باستخدام الجرافيك والموسيقي واللقطات التسجيلية .. بهدف جعلها أكثر تشويقاً للمشاهد حتي لا ينصرف عن المتابعة وجذب إنتباهه إلي الإستمرار لمشاهدة الفقرات التالية. 
ومن حيث المضمون:

- الإهتمام بتبسيط المحتوي العلمي الذي يعرض بالبرنامج، والتوجيه للضيوف من الخبراء

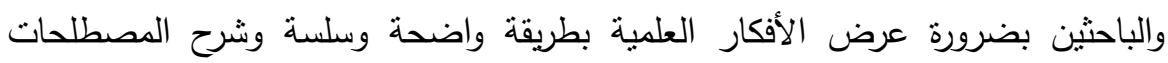
العلمية وتوضيحها للمشاهدين.

- زيادة كمية المشاهد التسجيلية المصورة من موقع المشروع أو الحدث بالإضافة إلي الإستعانه بأفلام وثائقيه تخدم موضوع الحلقة من مكتبات الجهات العلمية والبحثنية المعينة

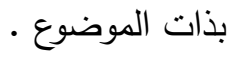

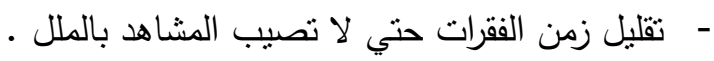
- تعدد الفقرات لتشمل جوانب الموضوع المختلفة واعطاء الفرصه لأكبر عدد من الخبراء لشرح كافة النواحي. r- مقياس القيم البيئية: تم بناء مقياس القيم البيئية بطريقة منهجية بدءا من تحديد الهدف

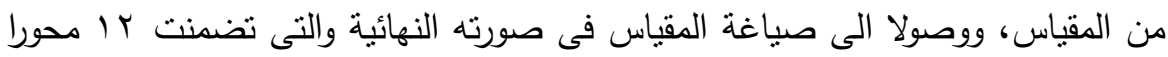
أو بعدا نشمل بع فقرة. وتم تقنين المقياس بتعيين الصدق والثبات: > الصدق ( صدق المحكمين ) وفى ضوء اتفاق المحكمين تم الابقاء على المفردات التى واتى

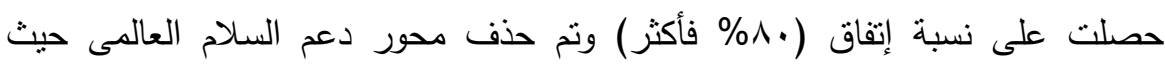
حصل على نسبة إتفاق أقل من ( •^\%) من عدد المحكمين .

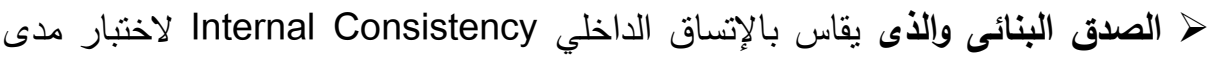

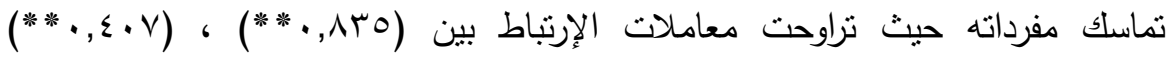
وجميعها دالة عند مسنوى دلالة (1 (., •).

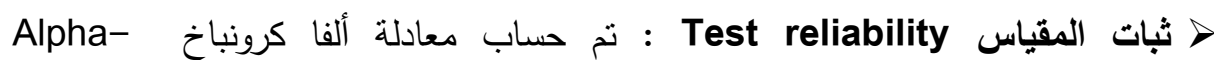
Cronbach's وقد جاءت معاملات الثبات مرتفعة في كل المحاور، وتراوحت ما بين

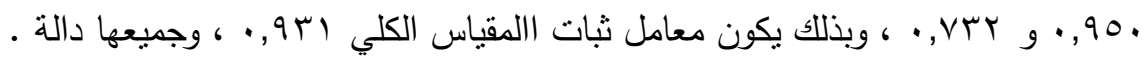


> تطبيق المقياس:

• تم إختيار عدد 7 حلقات من كلٍ من برنامجى: (سواعد مصرية "ق ا"و الكوكب الأخضر

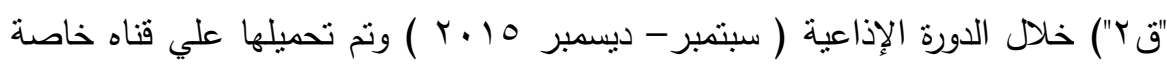

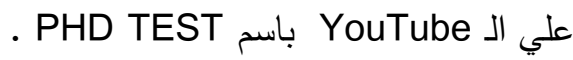

• تم عرض الموضوع من قبل الباحث على الطلبة وتوضيح المقياس والغرض منه وكيفية

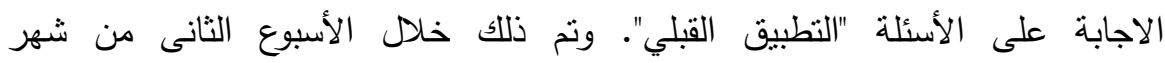

ديسمبر 10 • ب، بأحد قاعات الاطلاع بدار الكتب المصرية.

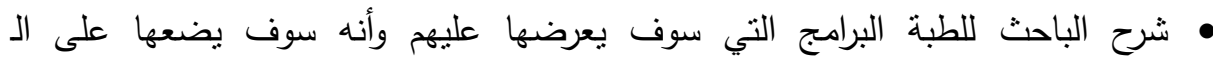

. وoutube

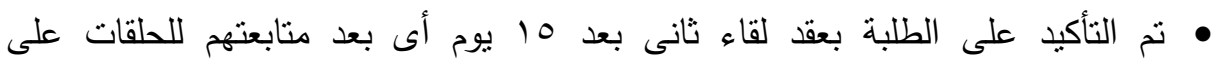
الانترنت.

• قام الباحث تطبيق مقياس القيم البيئية "النطبيق البعدي" خلال الأسبوع الأول من شهر يناير 17 ـ ب r، على نفس المجموعة بعد مشاهدتهم الحلقات، وبنفس مكان التطبيق القبلى.

\section{مجالايت الصراسه}

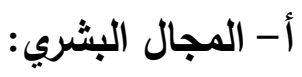

المجموعة الأولى: تكونت عينة الدراسة من ·r طالبا من جامعة القاهرة ( • ( ذكور و •

المجموعة الثانية: تكونت عينة الدراسة من •r طالبا من جامعة عين شمس( • • ذكور و • ( إناث ). ب- المجال الجغرافي: تم اختيار عينة عشوائية من طلاب و طالبات جامعة القاهرة وجامعة عين شمس. 
ث- المجال الزمانى: حتى تم نطبيق الجزء الميداني للبحث خلال الدورة الاذاعية

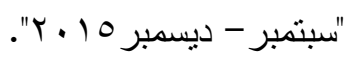

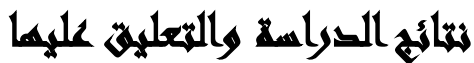

أولا: كثفت نتائج تحليل المضمون "من حيث الشكل والمحتوى" عن : جدول رقم(1) : توزيع برامج العلوم والتكنولوجيا وفقاً لتوقيت الاذاعة

\begin{tabular}{|c|c|c|c|c|c|c|}
\hline إجمالي & فترة المساء & فتي الظهيرة الضحي & الصباحية & لتحليل & & القتاه \\
\hline$\overline{7}$ & & $\overline{7}$ & & عدد & سو اعد & \multirow{6}{*}{ الاولي } \\
\hline$\%$ Y & & \%ro & & نسبيه & مصريه & \\
\hline 7 & 7 & & & عدد & \multirow{2}{*}{ كونكت } & \\
\hline$\%$ Yo & \% Yo & & & نسبه & & \\
\hline$I T$ & 7 & 7 & & عدد & \multirow{2}{*}{ جمله } & \\
\hline$\% 0$. & $\%$ Yro & $\%$ ro & & نسبه & & \\
\hline 7 & & & 7 & عدد & \multirow{2}{*}{ الاخوكبر } & \multirow{6}{*}{ الثانية } \\
\hline$\%$ Yo & & & $\%$ \% & نسبه & & \\
\hline 7 & 7 & & & عدد & \multirow{2}{*}{ هاي تلك } & \\
\hline$\%$ Yo & $\%$ \% & & & نسبه & & \\
\hline IT & 7 & & 7 & عدد & \multirow{2}{*}{ جمله } & \\
\hline$\% 0$. & $\%$ \% & & $\%$ \% & نسبه & & \\
\hline$T \xi$ & $I T$ & 7 & 7 & عدد & & \multirow{2}{*}{ الاجمالي } \\
\hline$\% 1 \ldots$ & $\% 0$. & \% Yo & \% Yo & نسبه & & \\
\hline
\end{tabular}

ومنه يتضح أن القناة الاولي توزعت برامجها بالتساوي بين فترة الضحي والظهيرة وفترة

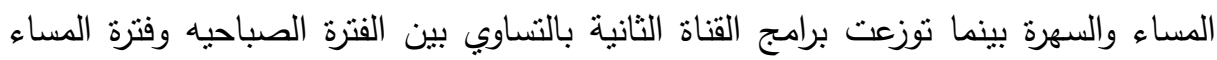
والسهرة. وبمقارنة هذة النتائج بنتائج بحوث واسنطلاعات راي المشاهدين حول الفترات الاكثر مشاهدة للتلفزيون والتي جاءت علي النحو التالي طبقاً لنتائج بحث أنماط مشاهدة التليفزيون

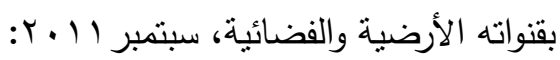

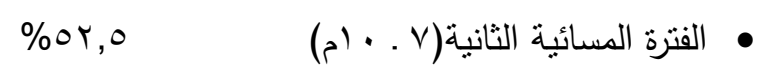

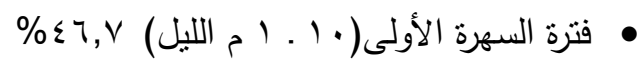

$$
\text { المجلد الثاني والثثلاثون، مارس } 17 \text { ـ ا ب }
$$




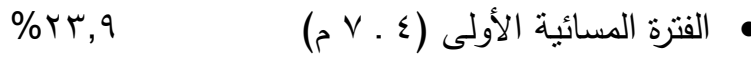

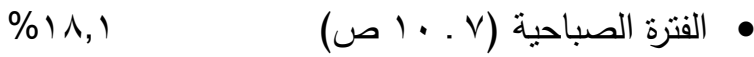

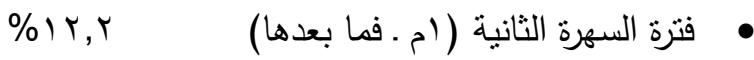

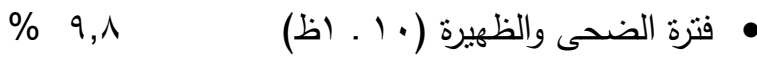

نجد أن برنامجاً واحداً في كل من القناة الاولي ( كونكت ) والقناة الثانية ( هاي تلك ) يقدمان في الفترة المساء والسهرة وهي من الفترات كثيفه المشاهدة، وبالتالي فإن إمكانية نجاحهما أقوى في الوصول إلي المشاهدين في نوقيتات مناسبة لتحقيق التأثير المطلوب (وفقاً لنظرية الفرس الثقافى). جدول رقم(ץ): توزيع برامج العلوم والتكنولوجيا تبعاً لاستخدام الاسنمالات العاطفية والمنطقية

\begin{tabular}{|c|c|c|c|c|}
\hline إجمالي & جملة الاستثمالات & جملة الاستيمالات & التحليل & القتاه \\
\hline rᄉ & 19 & 19 & عدد & \multirow{2}{*}{ القناة الاولي } \\
\hline$\% 1 \ldots$ & $\% 0$. & $\% 0$. & نسبه & \\
\hline 00 & ro & $r$. & عدد & \multirow{2}{*}{ القناة الثانية } \\
\hline$\% \quad \ldots$ & $7 \pi, 7$ & $\Gamma \eta, \varepsilon$ & نسبه & \\
\hline $9 \pi$ & $0 \xi$ & rq & عدد & \multirow{2}{*}{ الاجمالى } \\
\hline$\% 1 \ldots$ & $\% \circ \wedge, 1$ & $\% \leq 1,9$ & |نسبه & \\
\hline
\end{tabular}

وقد ارتفع معدل استخدام الاستمالات العاطفية إلي اقصي مدي 63.6\% \%اخل برامج

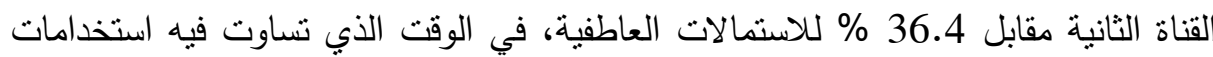
الاستمالات العاطفية والمنطقية .0 \% لكل منهما داخل برامج القناة الأولي وهو ما يؤكد

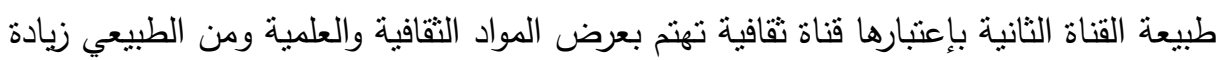

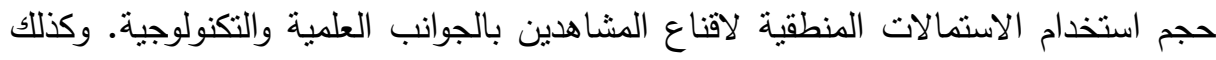
إقناعهم بتبني الافكار والسلوكيات العصرية التي تخدم المجتمع والبيئة. أ- استخدام الاستمالات العاطفية في برامج العلوم وإلتكنولوجيا بالقتاتين الأولي وإلثانية: جاءت " دعوات التحضر والتمدين في المرتبة الأولي 71.8\% بين الاستمالات العاطفية

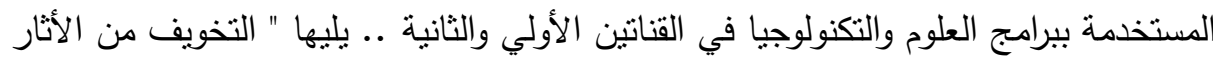
السلبية " 25.6\% . 
وقد جاء استخدام البعد الديني في الترتيب الأخير 2.6\%، بين عينة الدراسة التحليلية

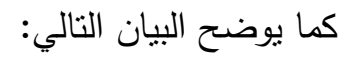

جدول رقم(ץ): توزيع برامج العلوم والتكنولوجيا تبعاً لاستخدام الاستمالات العاطفية

\begin{tabular}{|c|c|c|c|c|c|c|}
\hline إجمالي & التحضرات & البعد الاينخى & التخويفية & فئة التحليل & & القتاة \\
\hline 11 & 7 & & 0 & عدد & \multirow{2}{*}{ سصريد } & \multirow{6}{*}{ الاولي } \\
\hline$\%$ & $0 \leqslant, 0$ & & $\varepsilon 0,0$ & نسبه \% & & \\
\hline$\Lambda$ & 7 & 1 & 1 & عدد & \multirow{2}{*}{ كونكت } & \\
\hline$\%$ & $v 0, \cdot$ & 1,0 & 1,0 & نسبه \% & & \\
\hline 19 & IT & 1 & 7 & عدد & \multirow{2}{*}{ جمله } & \\
\hline$\%$ & $7 \pi, 1$ & $0, \pi$ & 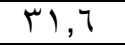 & نسبه \% & & \\
\hline 1. & 7 & & $\varepsilon$ & عدد & \multirow{2}{*}{ الاخضر } & \multirow{6}{*}{ الثانية } \\
\hline$\%$ & $7 ., 9$ & & $\varepsilon \cdot, \cdot$ & نسبه \% & & \\
\hline 1. & 1. & & & عدد & \multirow{2}{*}{ هاي تلك } & \\
\hline$\%$ & $1 \ldots$ & & & نسبه \% & & \\
\hline$r \cdot$ & 17 & & $\varepsilon$ & عدد & \multirow{2}{*}{ جمله } & \\
\hline$\%$ & $\Lambda \cdot, \cdot$ & & $r \cdot, \cdot$ & نسبه \% & & \\
\hline$r q$ & rA & $\frac{1}{1}$ & 1. & عدد & \multirow{2}{*}{\multicolumn{2}{|c|}{ الاجمالي }} \\
\hline$\% 1$. & $\overline{V I, \Lambda}$ & $\overline{Y, T}$ & $Y 0,7$ & - & & \\
\hline
\end{tabular}

ويتضح أيضاً أن القناة الثانية كانت الأعلي في إستخدام " دعوات التحضر والتددين بنسبة •, •^ \% مقابل 63.1 بالقناة الأولي • بينما زاد إستخدام " التخويف من الأثار السلبية

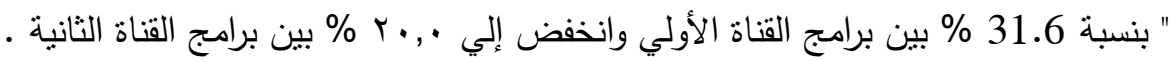

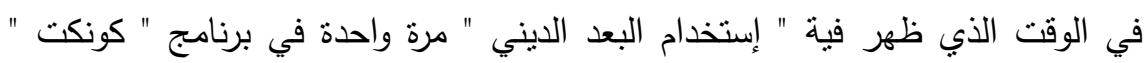

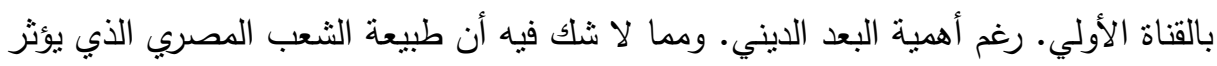

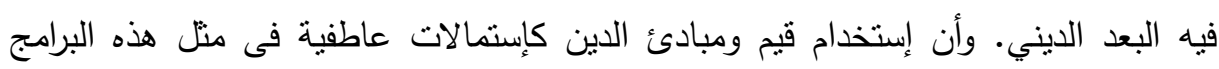
سيكون له أثر بالغ في التأثير علي المشاهدين وإقناعهم بتبني القيم والسلوكيات البيئية الدفيدة ل المجتمع والأفراد. 
ب - استخدام الاستمالات المنطقية في برامج العلوم والتكنولوجيا بالقتاتين الأولي والثانية:

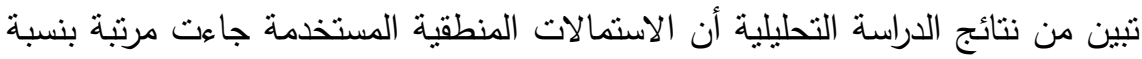
ورودها في البرامج كما يلي:

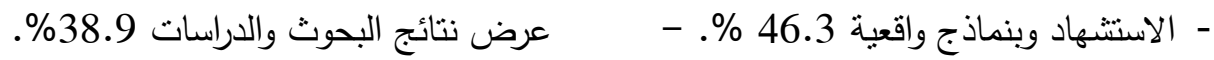

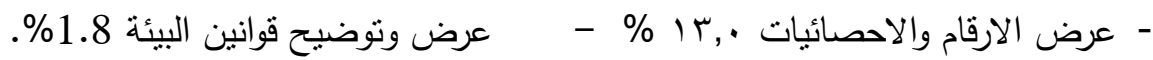
جدول رقم(؛ ): نوزيع برامج العلوم والتكنولوجيا تبعاً لاستخدام الاستمالات العاطفية

\begin{tabular}{|c|c|c|c|c|c|c|c|}
\hline إجمالي & ع قوانينية & والبتراتئ & باقتماذجة الاستشهاد & والاحصائيات & & & تار \\
\hline IT & & 0 & 7 & 1 & عدد & \multirow{2}{*}{ سوراعد } & \multirow{6}{*}{ الاولتي } \\
\hline$\ddot{\%}$ & & $\varepsilon 1, V$ & $0 ., \cdot$ & $\wedge, r$ & نسبه \% & & \\
\hline $\mathrm{V}$ & & 1 & 0 & 1 & عدد & \multirow[b]{2}{*}{ كونكت } & \\
\hline $\begin{array}{l}1 \ldots \\
\%\end{array}$ & & $1 \varepsilon, r$ & 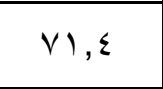 & $1 \varepsilon, r$ & نسبه \% & & \\
\hline 19 & & 7 & 11 & $r$ & عدد & \multirow[b]{2}{*}{ جمله } & \\
\hline$\%$ & & $r, 7$ & ov, $q$ & $1 \varepsilon, r$ & نسبه \% & & \\
\hline $1 \leq$ & 1 & 7 & 0 & $r$ & عدد & \multirow{2}{*}{ الاخضز } & \multirow{6}{*}{ |الثانية } \\
\hline$\ddot{\%}$ & $V, r$ & $\varepsilon r, \Lambda$ & $r 0, V$ & $1 \varepsilon, r$ & نسبه \% & & \\
\hline YI & & 9 & 9 & $r$ & عدد & \multirow{2}{*}{ تكاي } & \\
\hline$\%$ & & $\leqslant r, \Lambda$ & $\sum r, \Lambda$ & $1 \varepsilon, \varepsilon$ & نسبه \% & & \\
\hline ro & 1 & 10 & $1 \leq$ & 0 & عدد & \multirow[b]{2}{*}{ جمله } & \\
\hline $1 \ldots$ & $r, q$ & $\varepsilon r, \Lambda$ & $\varepsilon \cdot, \cdot$ & $1 \varepsilon, r$ & نسبه \% & & \\
\hline $0 \leqslant$ & 1 & $r 1$ & ro & $\mathrm{V}$ & عدد & \multirow{2}{*}{\multicolumn{2}{|c|}{ الاجمالي }} \\
\hline$\ddot{\%}$ & 1,1 & rᄉ, 9 & $\leq 7, r$ & $1 \%, \cdot$ & نسبه \% & & \\
\hline
\end{tabular}


وقد ورد " الاستشهاد بنماذج واقعية " في الترتيب الأول ov,9 \% \% بين برامج القناة

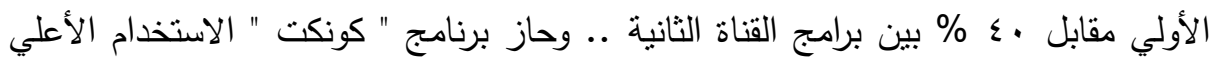

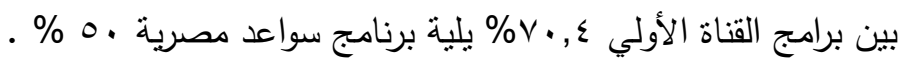

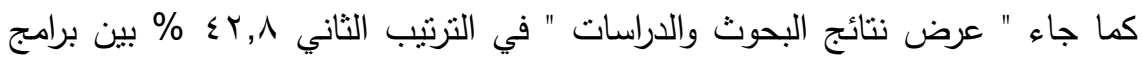

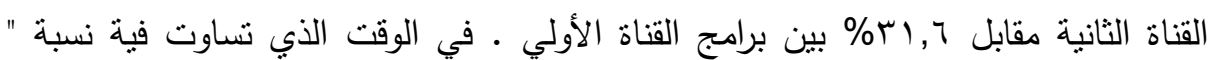
عرض الارقام والاحصائيات " ب,ـا ا \% في كل من القناة الأولي والثانية.

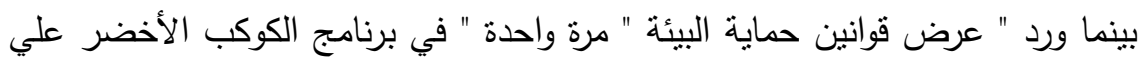
القناة الثانية .. رغم أهميته في توعية المشاهدين بهذا الجانب الحيوي في الحفاظ علي البيئة وحمايتها . أهم الموضوعات التي ناقشتها برامج العلوم والتكنولوجيا: تركزت أهم الموضوعات التى تتاولتها حلقات برامج العلوم والتكنولوجيا فيما يلى:

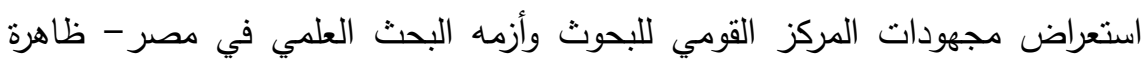
الاحتباس الحراري وأثرها في التغيرات المناخية وتأثنرها علي الدلتا المصرية وشواطئ البحر لهر المتوسط - الاستشعار في خدمة نطوير الزراعة - معالجة المخاطر البيئية : $\}$ معالجة المياة: وتتقيتها \} مياة صرف. مياة جوفيه \{ الصرف القياسي - إستصلاح الاراضي وتتمية الصحراء

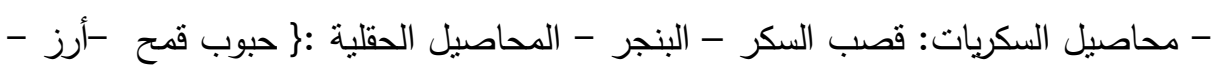
عس -شعير - فول- علف الحيوانات - محاصيل الزيوت - محاصيل الالياف\{ - دور الهندسة الوراثية في تتمية المحاصيل الزراعية وزراعة أنسجة النبات - دخول مصر عصرير الاستخدامات السليمة للطاقة النووية ومشروع إنشاء اول محطة للطاقة النووية - الهندسة

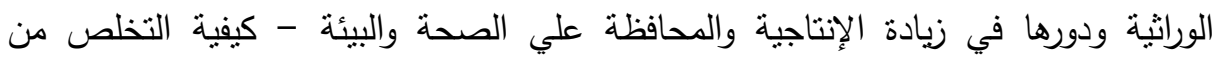
النفايات بطرق ووسائل حديثة باستخدام تكنولوجيا العصر - إستخدامات التكنولوجيا الجديثة في الزراعة - تربية النحل: Pie House فوائد النحل: "الصحية -الاقتصادية - إنشاء خلية نحل بالمنزل البيئة - إستخلاص سم النحل - تلقيح النبات - الغابات الثجرية: "غابات طبيعية في الخارج - غابات أثجار خشبية في مصر" - الاشجار الخشبية: "أهميتها

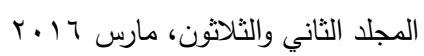


الاقتصادية - أهيتها البيئية - تشجير الطرق - الوعي الارشادي بفوائد الاشجار الخشبية" -

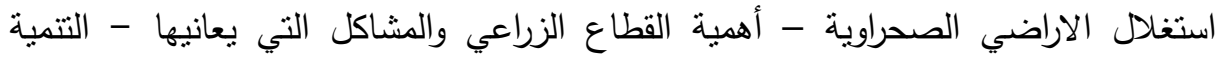
المستدامة وإستغلال الموارد بشكل منوازن - المحاصيل البستانية: "الخضار والفواكة". ثانيا: أهم نتائج مقياس القيم البيئية: جدول رقم(ه): يوضح دلالة الفروق بين الثباب فى القيم البيئية قبل وبعد مشاهدة برامج العلوم والتكنولوجيا

\begin{tabular}{|c|c|c|c|c|c|c|c|}
\hline الدستوية & قيمة T & الحرية & الإنحعرافى & الحستوسط & العدد & العينه & التباين \\
\hline \multirow[t]{2}{*}{ "' دالة ", ". } & \multirow[t]{2}{*}{$\varepsilon, 91 \cdot-$} & \multirow[t]{2}{*}{$r q$} & r & Аr, & $\varepsilon$. & الشباب فيل & \multirow{2}{*}{ البيئية } \\
\hline & & & $0, V \leqslant$ & 91,10 & $\varepsilon$. & الثشباب بعدة & \\
\hline
\end{tabular}

يتضح من الجدول السابق أن :

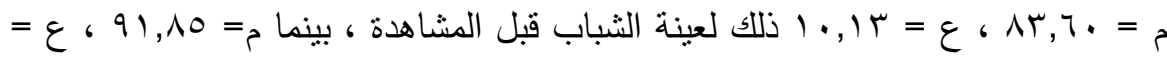
0,V ع وذلك لعينة الثباب بعد المشاهدة .

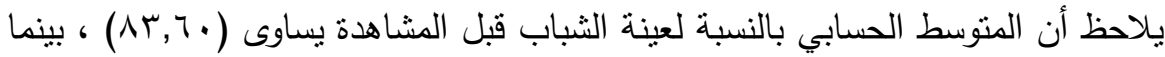

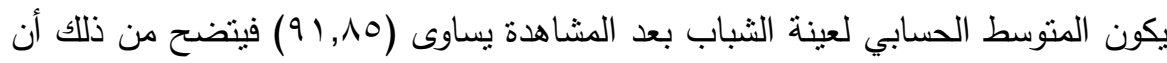

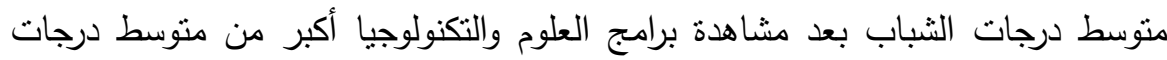
الثباب قبل مشاهدة برامج العلوم والتكنولوجيا .

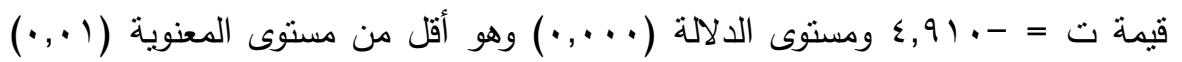
وبالتالى - توجد فروق ذات دلالة إحصائية بين الثباب قبل وبعد مشاهدة برامج العلوم والتكنولوجيا " فى القيم البيئية لصالح التطبيق البعدى، مما يبين نأثير تطوير برامج العلوديه والتكنولوجيا على تتمية القيم البيئية لدى الثباب، اهتمت دراسة محمود محمود

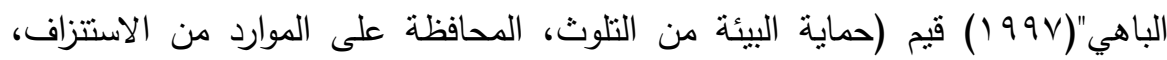

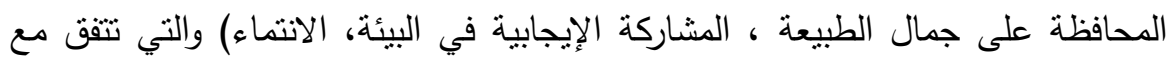
الدراسة الحالية ، اتفقت مع دراسة (Ray 1994) عدم وجود فروق ذات دلالة إحصائية 
بين اتجاهات المبحوثين نحو القضايا والمشاكل البيئية العالمية، كالتلوث الإثعاعي وتلوث المياه والتصحر والاحتباس الحراري وغيرها من القضايا والمشكلات البيئية على المستوى العالمي..

وقد جاءت النتائج التفصيلية لكل محور من محاور مقياس القيم البيئية متفقة مع نتائج السابقة. جدول رقم(7): يوضح دلالة الفروق بين الذكور والإناث فى القيم البيئية قبل مشاهدة برامج العلوم والتكنولوجيا المطورة

\begin{tabular}{|c|c|c|c|c|c|c|c|}
\hline مستوي & 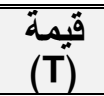 & الدرجية & الإلإنحرافياف & الحستوسي & العدد & العينـه & مصبدر \\
\hline \multirow{2}{*}{ 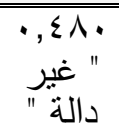 } & \multirow[t]{2}{*}{$\cdot, V \backslash \leqslant$} & \multirow[t]{2}{*}{ rᄉ } & $1,, .9$ & $\Lambda \varepsilon, \vee 0$ & r. & الإناث & \multirow{2}{*}{ البيئية } \\
\hline & & & $1 \cdot, r r$ & $\Lambda Y, \leqslant 0$ & $r$. & الأكور & \\
\hline
\end{tabular}

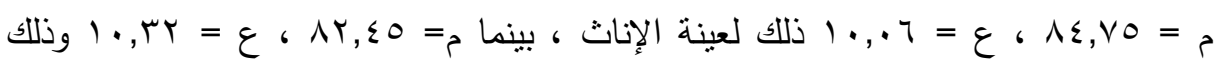

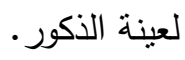

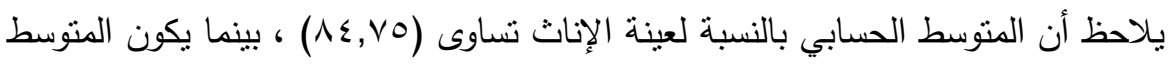

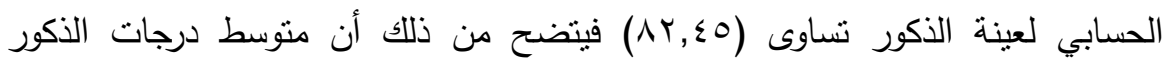

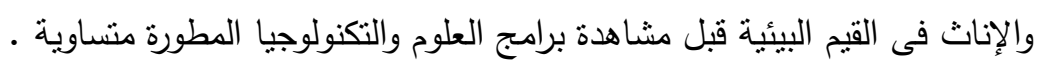

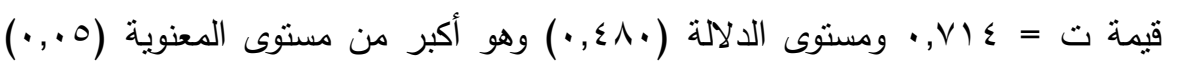

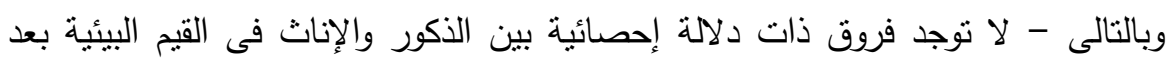

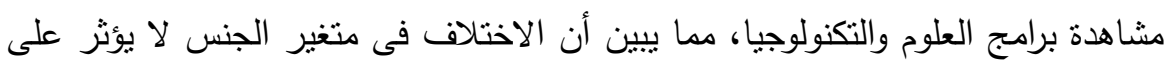

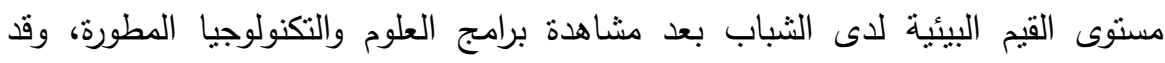

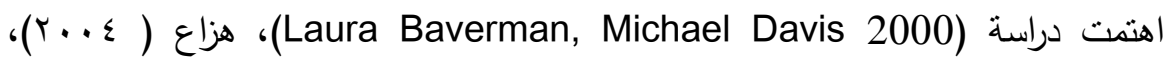

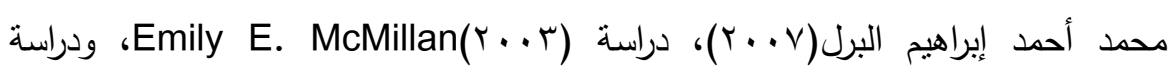
إبراهيم المسلمى (1991 (1) بدراسة القيم البيئية والتي اهتمت بهاسية التها الدراسة الحالية. 
جدول رقم(V): يوضح دلالة الفروق بين الذكور والإناث فى القيم البيئية بعد مشاهدة برامج العلوم والتكنولوجيا المطورة

\begin{tabular}{|c|c|c|c|c|c|c|c|}
\hline مستوية الدلائي & قيمة & الدرجة & الإِنيارَف & الحستوسطي & العدد & العينه & مصباينر \\
\hline \multirow{2}{*}{ " غير دالة " עr " } & \multirow{2}{*}{., १९९- } & \multirow{2}{*}{ ґ^ } & 0,011 & $9 \cdot, 90$ & $r$. & الإناث & \multirow{2}{*}{ البيئية: } \\
\hline & & & 0,900 & $9 Y, V_{0}$ & $r$. & الذكور & \\
\hline
\end{tabular}

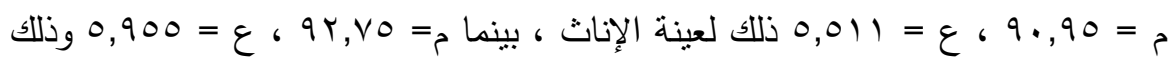
لعينة الذكور •

يلاحظ أن المتوسط الحسابي بالنسبة لعينة الإناث تساوى (90, • 9) ، بينما يكون المتوسط

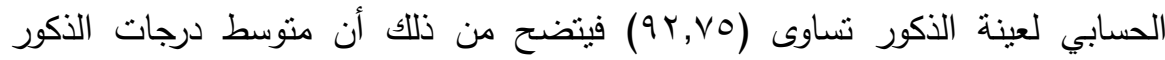

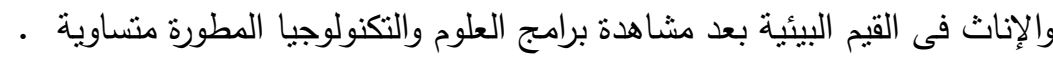

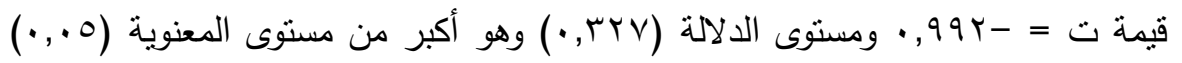

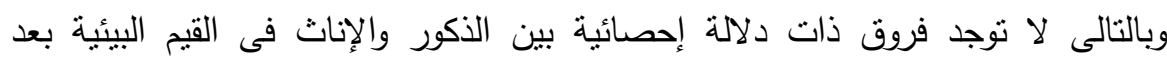

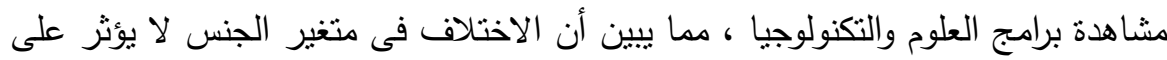

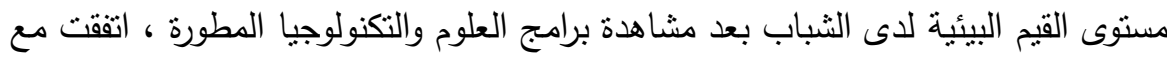
دراسة لا توجد فروق ذات دلالة إحصائية بين الطلاب من الجنسين في مقياس القيم البيئية، تميز طلاب الكليات العملية بارتفاع درجاتهم عن الكليات الأدبية في مقياس القيم البيئية في قيمة مكافحة التلوث وحماية البيئة ومواجهة المشكلة الغذائية، بينما تفوق طلبة بلية الكليات الأدبية في قيمة الجمال البيئي التي تميزت فيها الإناث عن الذكور أيضاً، واختلفت مع دراسة يحيى محمد أبو جحجوح "(999) وجود أثز دال إحصائياً عند فئئ مستوى دلالة (0.، · ) لمتغير الجنس في مسنوى القيم البيئية لصالح الطالبات. 


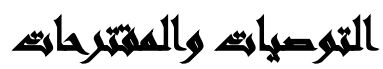

1-يجب عرض برامج العلوم والتكنولوجيا التي تتتاول القضايا البيئية في مواعيد كثافة

المشاهدة المرتفعة وهي "الفترة المسائية ،وفترة السهرة".

r-نظوير برامج العلوم والتكنولوجيا من حيث الثكل والمضمون واستخدام تقنيات الانتاج

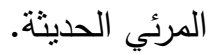

r-ضرورة تعاون التليفزيون المصري مع وزارة البيئة ومؤسسات العمل المدني في انتاج

برامج مرئية لمعالجة قضايا البيئة.

ع- اتاحة الفرصة المشاهدين في مشاركة في برامج العلوم والتكنولوجيا لتحقيق التاعلية

ووصول الرسالة الاعلامية وتحقيق الرسالة المضمونة.

ه-الاستعانة بضيوف من الخيراء والمتخصصين في موضوع الحلقة لتحقيق الاستفادة القصوى للمشاهدين.

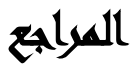

اتحاد الإذاعة والتليفزيون: الإدارة المركزية للتخطيط والانجازات - الخطة الإعلامية العامة

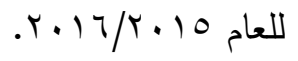

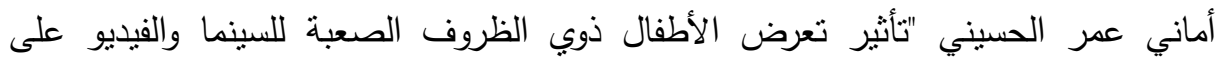
إدراكهم الواقع الاجتماعي" رسالة ماجسنير - - غير الإطير منشورة - القاهرة - كلية

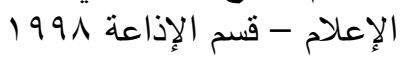

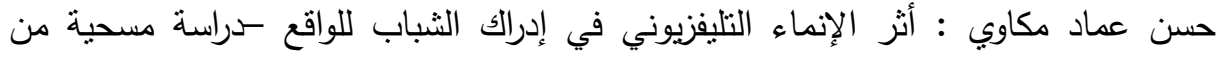

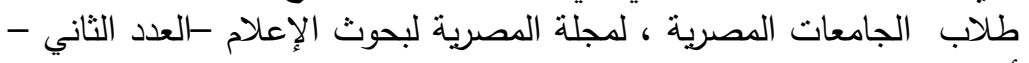

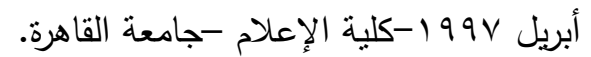

سامية دسوقي عبد الله : "دور التليفزيون في إمداد المرأة المصرية بالمعلومات البيائية" رسالة

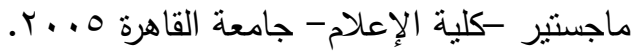

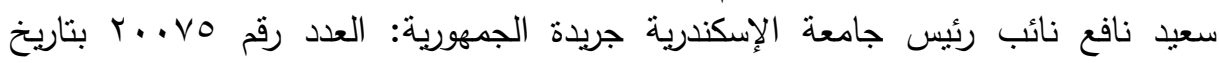

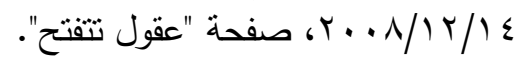

سوزان القليني، صلاح مدكور : الإعلام البيئي .. النظرية والتطبيق، بلتهب، دار النهضة العربية،

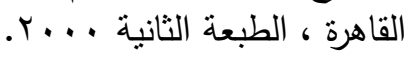

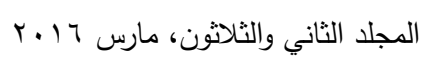


عماد الدين عبد المجيد الوسيمي دراسة تحليليه للقيم البيئية المتضمنة في مناهج الأخبار

بالمرحلة الثانوية، مجلة كليه التربية ، جامعه الزقازيق ، العدد بائ، 1990

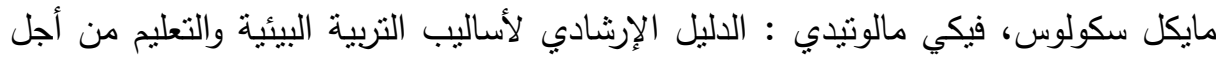

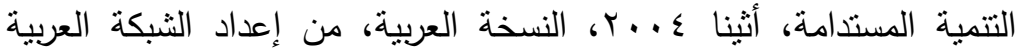

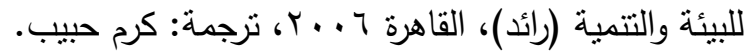

نهلة مظفر ( . . †): برامج التوعية البيئية فى التليفزيون المصرى والسورى، رسالة ماجستير،

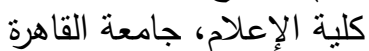

الوثيقة النهائية لمؤتمر الأمم المتحدة للبيئة والتتمية ، ريو دي جانيرو - البرازيل - يونيو .1994

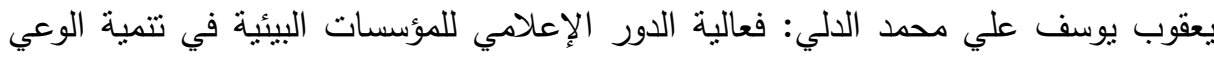

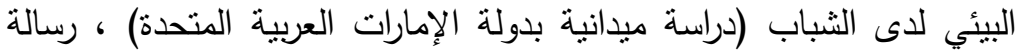

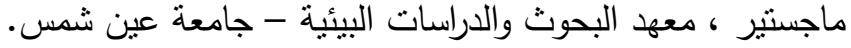

Becker, S.L. discovering mass communication U S A: scott, foresman and company2nd edition) ‘.1987) (p.402.

Singnorielli, N., \& Morgan, M. cultivation analysis, new directions in media effects research California. SAGE publications, Inc. (1990).

Mc Quail's "Mass Communication Theory" (London, sage publication ltd, 2000, 4th edition) P464

Richard Campbell \& (etal) "media \& culture an introduction to mass communication" third edition (new York, Bedford Ist martin's Boston 2003 .

Michael B salwen \& dawn w.stacks "an integrated Approach to communication theory and research" (new jersey: Lawrence Erlbaum, Associate publishers, 1996.

Fiecher,Henry W: llurrieanc gilbert, the university of Colorado, the national research and applications center, 1989.

1-Emily E. McMillan, (2003) The Effectiveness of Environmental Education: How environmental education influences students' personal 
محب محمود كامل الرافعي وآخرون

environmental ethics, MES Unpublished Thesis, Graduate of Dalhousie University ,School for Resource and Environmental Studies, February 1- Laura Baverman, \& Michael Davis, (2000) The Attitudes of People towards Nature, (www.muohio.edu).

\title{
THE DEVELOPMENT OF SOME SCIENCE AND
}

TECHNOLOGY PROGRAMS IN THE EGYPTIAN

\section{TELEVISION, AND ITS IMPACT ON DEVELOPING ENVIRONMENTAL VALUES AMONG YOUTH}

El-Rafii, M. M. K. ${ }^{(1)}$; Mekkawi, H. I. $^{(2)}$ and Ahmadein, M. M. M. ${ }^{(3)}$

1) Institute of Environmental Studies and Research, Ain Shams University 2) Faculty of Mass Communication, Cairo University 3) Chairman of Company "Cable Network Egypt" ( CNE )

\begin{abstract}
The study aimed at developing environmental values for youth through the development of some programs on science and technology broadcasted on the Egyptian Television, and showing its impact on the development of environmental values among youth.

The researcher has used several tools for data collection, namely:

- content analysis form

(24) Episodes have been analyzed, distributed on (4) programs (on Channels 1 and 2) \{6 episodes of each program $\}$ during the period (September to December 2015), and developing 2 programs, in addition to the design of

- Environmental values scale which has been applied to (40) Ain

Shams and Cairo University students, divided into (20) Ain Shams

University and Cairo University male students, and 20 Ain Shams
\end{abstract}

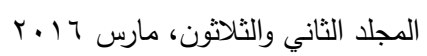




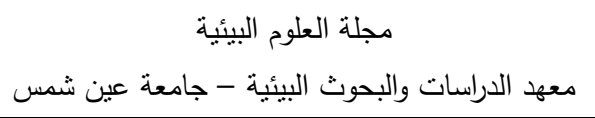

University and Cairo University female students . This was applied before and after watching on the same sample.

The most important findings of the study include:

1- There are differences in statistical significance between youth before and after watching science and technology programs concerning environmental values in favor of post - watching, which shows the effect of developing science and technology programs on developing environmental values for youth.

2- There are no statistically significant differences between male and female students concerning environmental values after watching science and technology programs, which shows that the difference in the gender variable does not affect the level of environmental values among youth after watching the developed programs on science and technology.

3- Most of the science and technology programs don't reveal interest in the participation of viewers, thus losing the interaction with viewers, who are the target by these programs.

4- Science and technology programs include many positive environmental values which affect the viewers, but it lack the attractive Showing. 